\title{
Examining the relationship between pubertal stage, adolescent health behaviours and stress
}

\author{
A. E. SiMON, J. WARDLE, ${ }^{1}$ M. J. JARViS, N. STEGGLES And M. CARTWRIGHT \\ From the Cancer Research UK Health Behaviour Unit, Department of Epidemiology and Public Health, \\ University College London
}

\begin{abstract}
Background. This paper examines the associations between puberty and three important health behaviours (smoking, food intake and exercise) and explores whether these associations are mediated by puberty's relationship to stress and psychological difficulties.

Method. Data were taken from the first year of the ongoing, 5-year, Health and Behaviours in Teenagers Study (HABITS). This is a school-based study set in 36 schools in London. In the first year of the study, 4320 students (2578 boys, 1742 girls) in their first year of secondary education took part.
\end{abstract}

Results. Among girls, being more pubertally advanced was associated with a greater likelihood of having tried smoking. Among boys, being more pubertally advanced was associated with a greater likelihood of having tried smoking, a higher intake of high-fat food and higher levels of exercise. More pubertally advanced girls experienced more stress but not more psychological difficulties. There were no associations between puberty and either stress or psychological difficulties in boys. Stress and psychological difficulties were associated with health behaviours in girls and boys, but neither of these factors mediated the relationship between pubertal stage and health behaviours found in girls.

Conclusions. These results suggest that the onset of puberty has a marked effect on the development of health behaviours. Puberty was related to an acceleration of the development of unhealthy behaviours, except for exercise behaviour in boys, where advanced puberty was associated with more exercise. These changes were unrelated to adolescent issues of stress and a causal explanation for these associations must be sought elsewhere.

\section{INTRODUCTION}

Puberty is a period of rapid hormonal, physiological and physical changes. These dramatic changes might be expected to engender some psychological effects, insofar as they represent a developmental transition for which the individual is not always fully prepared. Onset of puberty has been associated with a range of social and emotional effects (Steinberg \& SheffieldMorris, 2001). Behaviour changes also appear,

\footnotetext{
1 Address for correspondence: Professor Jane Wardle, Cancer Research UK Health Behaviour Unit, Department of Epidemiology and Public Health, University College London, 2-16 Torrington Place, London WC1E 6BT.
}

including varied sleeping and eating patterns (Gillman et al. 2000; Laberge et al. 2001), new sexual behaviours (Goodson et al. 1997) and involvement in delinquency and substance use (Williams \& Dunlop, 1999; Dick et al. 2000).

The hormonal and physical changes of puberty will have a direct influence on some aspects of emotion and behaviour. In addition, the perception of changes by the adolescents themselves, or the reactions of others to their more adult bodies, could play a part. There is evidence that the timing of puberty influences the individual's reactions. Being pubertally 'off-time', i.e. early or late compared to others in the social group, has been hypothesized to be stressful 
(Petersen \& Taylor, 1980). This is partly because the 'off-time' adolescent is in the minority and may lack the social or institutional support that smooths the transitional path for the 'on-time' individuals (Alsaker, 1996). The stress of off-time puberty has been hypothesized to lead to adaptive problems, which display themselves in the form of emotional problems or delinquency (Williams \& Dunlop, 1999). An alternative hypothesis is that only early maturers are at particular risk because their physical maturity means that both adults and peers attribute to them a psychological maturity that may outstrip their actual development (Stattin \& Magnusson, 1990). Early maturing girls tend to develop friendship networks with other equally mature, and therefore older girls, where more 'adulttype' behaviour is acceptable (Silbereisen et al. 1989). Early maturers may also perceive themselves as more grown-up and emulate 'adult' behaviour, such as smoking and dieting. A conflict can arise because these behaviours, which are acceptable within the adult world, are perceived by adults to be 'norm-breaking' or rule transgressing in teenagers (Alsaker, 1996).

Behavioural research in this field has had a particular focus on behaviours such as substance abuse and delinquency (Tschann et al. 1994; Williams \& Dunlop, 1999; Dick et al. 2000), which pose problems in the adolescent years, compromising family and social relationships, as well as educational progress. Delinquent behaviour peaks during mid-adolescence, then declines to pre-adolescent levels by the mid-twenties. This increase in delinquency may reflect a 'maturity gap' between biological maturity and access to adult roles in society (Moffitt, 1996). As regards substance use, studies have shown that early-maturing adolescents, but not all off-time adolescents, have higher substance use, including alcohol, marijuana and cigarette use (Tschann et al. 1994; Harrell et al. 1998). Early menarche has also been associated with earlier and more frequent smoking and drinking (Dick et al. 2000).

Smoking has most often been examined in this broader context of substance use or in the delinquency context where it is represented as a 'transgressing act'. However, adolescence is also an important time for establishing health behaviours, and it is possible that the onset of puberty could be linked with a higher risk not only of smoking, but also of other health-compromising behaviours such as a sedentary lifestyle and an unhealthy diet. Early initiation of unhealthy behaviours might place the individual at higher risk for health problems in later life.

Research on exercise in adolescence shows that girls' participation in exercise is consistently lower than boys' participation (Lindquist et al. 1999; Lasheras et al. 2001). Boys' interest in school-based physical education (PE) remains relatively stable throughout secondary school, but girls' interest in PE, while higher than boys at younger ages, drops off, so that by the age of 14 the gender balance is reversed (Van Wersch et al. 1992). It has been suggested that PE loses its status as an important school subject for girls, because being 'good at sports' does not entail popularity for girls in the way that it does for boys (Van Wersch et al. 1992). Boys have also been shown to use exercise rather than dieting as their primary route for body shape change (Ricciaridelli et al. 1999). On the basis of these results, being more pubertally advanced might be expected to be associated with higher levels of exercise in boys and lower levels in girls. One study, which examined pubertal stage in relation to activity choices, found that higher pubertal stage was associated with an increase in sedentary activities in girls, although there was no such association in boys (Bradley et al. 2000).

Energy intake has been investigated in relation to pubertal stage in a number of studies, but there are few studies of food choices. Total energy intake increases across pubertal stage, peaking for girls at Tanner stage 3, and continually increasing with stage for boys (Clavien et al. 1996), although after controlling for body weight, the more pubertally advanced adolescents are not consuming more in relation to their body weight. Adolescence is a time when children take more responsibility for their own food choices, and are more likely to eat at different times from the family or away from the family home. Adolescents also appear to consume an excess of fat at the expense of carbohydrate and fibre intake (Clavien et al. 1996; Rolland-Cachera et al. 2000), and eat little fruit and vegetables (Neumark-Sztainer et al. 1996) although this has not been examined extensively in terms of pubertal development.

Some of the work relating pubertal stage to behavioural outcomes has considered the 
possibility that emotional factors provide the link with pubertal stage (Tschann et al. 1994; McCabe et al. 2001). Puberty has been shown to be related to depression, antisocial behaviour, aggression, anxiety, withdrawal and attention problems (Caspi \& Moffitt, 1991; Hayward et al. 1999). In addition, the increase in weight at puberty leads to body dissatisfaction and body change behaviour, such as dieting, that are also related to increased levels of anxiety (McCabe et al. 2001). However, few studies have directly tested the mediational model. One exception is a study by Tschann et al. (1994), which found that emotional distress did not appear to mediate the relationship between pubertal timing and substance use. This study's focus was an examination of substance use and it would be useful to both broaden the exploration of this topic to other kinds of health behaviours and to provide further evidence either to replicate or refute this finding.

The present study examines associations between puberty and three significant health behaviours: smoking, food choice and exercise and examines the hypothesis that emotional stress mediates the associations between puberty and behaviour. In this way, a fuller picture can be developed of the relationships between pubertal development, health behaviour and emotional distress. Data are taken from the baseline year of a 5-year cohort study, giving the advantage of a large, mixed-sex sample (Wardle et al. 2003).

\section{METHOD}

\section{Design}

The HABITS study is a 5-year longitudinal study of a cohort of adolescents attending 36 secondary schools in Greater London. The sample was stratified by school type (inner-city state; suburban state; privately funded) and gender mix (boys, girls, both). A list was compiled of all secondary schools in the South London boroughs taking students from the age of 11-16 years. Four schools were drawn at random from each of the nine cells formed by crossing the stratification factors. Each school was approached. If a school declined to take part a substitute was drawn from the list until all cells were complete. Twenty-eight schools declined to take part. Thirty-six schools who agreed to participate were identified. The data for this paper were from the first year of data collection between January and December 1999.

All students in the first year (age 11-12 years) of the secondary schools were eligible for inclusion $(N=5153)$. Parental approval was obtained prior to data collection in the form of a letter taken home from school by students. Parents returned forms to the school if they wished to exclude their child from the study. In the first year 4320 students ( 2578 boys and 1742 girls) in Year 7 took part. Eighty-four per cent of the total student body were present in the classes when data collection took place. Ten per cent were absent on the day of data collection, and $5.5 \%$ opted out of the study (either by parental or self-exclusion).

Participants completed a self-report questionnaire on smoking, diet, exercise, body image, pubertal development, stress, psychological health, and personality. Demographic information included ethnicity, gender, and socioeconomic status (SES). Smoking status was confirmed with a saliva cotinine test. Body size was assessed with height, weight, and waist circumference. Ethical approval for the study was obtained from the Joint UCL/UCH Committees on the Ethics of Human Research.

\section{Procedure}

Data collection was carried out in school classes under the supervision of at least two researchers. Data were collected annually during the Spring and Autumn terms, with 18 schools visited each term.

A researcher introduced the session by explaining the purpose, the procedure, the confidentiality of answers, and the voluntary nature of the study. An opportunity for the students to ask questions was provided. Students completed a sheet (with a unique identifier) detailing their name, address, school name, date and confirming their consent to participate. This was stored separately for anonymity and used to track students across the 5 years. Students completed the questionnaire and were individually weighed out of the sight of the other students. Saliva samples for cotinine testing were obtained using a dental roll placed in the side of the mouth for 10 min (Benowitz, 1996). 


\section{Measures}

\section{Pubertal stage}

Pubertal stage was assessed with items from the Pubertal Development Scale (PDS) (Petersen et al. 1988). The PDS was developed for use in schools, where other measures such as direct observation or explicit photographs (e.g. Sexual Maturation Scale (SMS); Tanner, 1962) are inappropriate. The PDS scale is correlated with the SMS $(r=0.72$ to $0 \cdot 80)$ (Brooks-Gunn et al. 1987). Students rate themselves on five items: growth spurt, pubic hair, skin changes, and, for girls, menarche and breast development and, for boys, voice change and facial hair. Scores from each item were summed (range 5 to 19). Petersen et al. (1988) report that this measure can be used either continuously or with a categorical, 'staging' classification. In this sample, a 5-stage classification system has been used: pre-pubertal (score 5), beginning pubertal (scores 6-10), mid-pubertal (scores 11-15), advanced pubertal (scores 16-18), and post-pubertal (score 19).

\section{Health behaviours}

Smoking status was assessed using two questions from the UK National Smoking Surveys (Goddard \& Higgins, 1999). The classification from these questions is: non-smokers (never smoked), tried smokers (tried only once), exsmokers (used to smoke), occasional smokers ( $<1$ a week), sometimes smokers (1-6 a week) and regular smokers ( $\geqslant 6$ a week). For some analyses, because cell sizes of regular smokers at this age were small, students were categorized into 'never smokers' and 'ever smokers'. Susceptibility to future smoking among nonsmokers was assessed using a scale developed by Pierce et al. (1996) that taps the pre-experimentation stage of the smoking onset process. The scale in this study is based on two items, referring to the possibility of smoking in the next 12 months and smoking a cigarette offered by a best friend. The response options are: 'yes definitely', 'yes probably', 'probably not' and 'definitely not'. If the respondent answers in any other way than 'definitely not' they are considered cognitively susceptible to experimentation with smoking.

Weekend exercise rates were measured by two questions developed for the study which asked if participants usually took part in sports or physical activities on Saturday and Sunday. The response options were dichotomous (yes/no). This indicated voluntary participation in extracurricular sports and provides a measure of exercise independent of compulsory school sports frequency, which shows considerable variation between schools. This variable is likely to reflect a social aspect of exercise behaviour.

Days per week exercised was assessed using a question developed in the Youth Risk Behaviour Surveillance System Questionnaire (YRBSSQ) (Heath et al. 1993). This asks how many days a person did exercise during the past week that made them 'sweat and breathe heavily'. The response ranged from no days to every day. This indicated overall exercise, including participation in sports at school.

Fruit and vegetable intake was assessed using two questions, originally based on items from the DINE (Roe et al. 1994) and used in a similar, modified format in other studies (e.g. Wardle et al. 2000). The questions asked: 'about how many servings of fruit/vegetables do you usually eat in a day?'. Response options ranged from less than one to five or more servings per day. The responses were summed to give a scale of $0-10$, ' 0 ' represents intake of less than one serving per day and ' 10 ' represents consuming five or more servings of fruit and five or more servings of vegetables per day.

Intake of high-fat foods was based on six items using a scale adapted from the 'foods that you eat scale' (Sweeting et al. 1994). These items related to intake of crisps, cakes, biscuits, chips, fried food and sausages/burgers. These items provide proportionally high levels of fat and are often used as 'snack' foods outside mealtimes. Intake was assessed on a six-point scale ranging from 'never/less than once a week' to 'more than once a day'. Scores were summed, producing a range from $0-30$, higher scores indicate higher intake. This scale had good reliability $($ alpha $=0 \cdot 78)$.

\section{Stress and psychological difficulties}

Psychological difficulties were measured using the 'Difficulties' score from the Strengths and Difficulties Questionnaire (SDQ) (Goodman et al. 1998). This is a brief behavioural screening questionnaire for use with children from age 4-16 years. The SDQ measures hyperactivity, emotional symptoms, conduct problems, peer 
problems and also has a pro-social scale. The pro-social scale is excluded when examining psychological problems. 'Difficulties' scores range from 0 to 34 with a higher score indicating more difficulties. In this sample it had good internal reliability (alpha $=0 \cdot 72$ ). The SDQ has good concurrent validity and is highly correlated with scores on the Rutter questionnaires (Goodman et al. 1998).

Stress was assessed with the 4-item version of the Perceived Stress Scale (PSS) (Cohen et al. 1983) a global measure of perceived stress. The scale ranges from 0 to 16 , higher scores indicate more stress. The PSS has good concurrent and predictive validity and is correlated in the expected direction with a range of questionnaires and behaviours (Cohen et al. 1983). This shortened version has relatively low internal reliability (alpha $=0 \cdot 6$ ) (Cohen \& Williamson, 1988), which was lower (alpha $=0.50)$ in the present sample, possibly because of the age of the respondents. Its advantage is that it is short and enables repeated measures of perceived stress in large samples.

\section{Demographic measures}

Demographic information included gender, age, self-reported ethnicity and SES. Students were asked their exact date of birth, and age in decimal years was calculated. Ethnicity was assessed with five response categories: white, black, Asian, mixed or other (specified). The categories 'mixed' and 'other' contained heterogeneous samples and were combined for the purpose of analyses. SES was assessed using indicators of material conditions in the family home. More traditional methods of assessing SES (e.g. parental occupation) are unreliable in lower SES adolescents (Wardle et al. 2002). Three material indicators were used: housing tenure, car ownership and possession of a dishwasher.

\section{Body Mass Index (BMI)}

BMI was derived from height and weight measurements.

\section{Analytical strategy}

Descriptive statistics are presented for the PDS scale and the demographic characteristics of the sample. Chi-square statistics and one-way analyses of variance (ANOVA) are then shown for the relationships between pubertal stage, demographics, health behaviours and psychological variables.

The data were then analysed using logistic and ordinal regressions showing the relationship of pubertal stage to health behaviours for each gender, while also controlling for SES, ethnicity, age and BMI. The dependent variables in the logistic regressions were: smoking status (tried smoking or not), susceptibility to smoking (susceptible or not) and weekend exercise (1-2 days or none) and in the ordinal regressions were: days per week exercised (0-7 days), fruit and vegetable intake (0-10 servings) and high-fat food intake (separated into deciles). In order to assess the possibility that stress/psychological difficulties mediate the relationship between pubertal stage and health behaviours, further regression analyses were carried out which compared odds ratios from a model that included stress/psychological difficulties and a model without these variables. The regression analyses were carried out in STATA v.7 and took account of school clustering and a combined weighting based on a weight for design and missing data. The design weight was based on the total number of schools in South London within each stratification cell and the refusal rate of the schools within each cell. The missing data weight took account of the proportionately greater amount of missing data from the lower SES and ethnic minority groups.

\section{RESULTS}

The demographic characteristics of the participants are shown in Table 1 . The average age of the students was 11.83 decimal years (S.D. $=$ $0 \cdot 35$ ). Approximately $40 \%$ of the participants considered themselves to be from non-white ethnic groups.

Table 1 also shows pubertal stage using the PDS scores. For both boys and girls, few are pre-pubertal, the majority are classified as 'beginning pubertal', with more boys than girls in this category, and more girls represented in the more advanced categories. This is to be expected at this age as girls mature earlier than boys. For most of the analyses, the sample was divided into three groups. This was developed because the cell sizes for boys who had reached advanced puberty and for girls who had still not begun puberty at this age were small. For girls the 
Table 1. Distribution of the sample by SES, ethnicity, pubertal stage, BMI and age

\begin{tabular}{lcc}
\hline \hline & $\begin{array}{c}\text { Girls } \\
(N=1742)\end{array}$ & $\begin{array}{c}\text { Boys } \\
(N=2578)\end{array}$ \\
& $11 \cdot 85(0 \cdot 32)$ & $11 \cdot 81(0 \cdot 37)$ \\
Age, mean (s.D.) & $19 \cdot 98(3 \cdot 84)$ & $19 \cdot 02(3 \cdot 40)$ \\
BMI, mean (s.D.) & & \\
SES quartiles, \% & $25 \cdot 2$ & $18 \cdot 7$ \\
$\quad$ Low & $25 \cdot 0$ & $21 \cdot 4$ \\
Medium & $27 \cdot 1$ & $31 \cdot 5$ \\
High & $22 \cdot 7$ & $28 \cdot 4$ \\
Highest & & \\
Ethnicity, \% & $21 \cdot 6$ & $15 \cdot 3$ \\
Black & $58 \cdot 1$ & $64 \cdot 3$ \\
White & $7 \cdot 8$ & $8 \cdot 9$ \\
Asian & $12 \cdot 6$ & $9 \cdot 8$ \\
Mixed/Other & & \\
Pubertal stage, \% & $2 \cdot 1$ & $8 \cdot 1$ \\
Pre- & $53 \cdot 1$ & $73 \cdot 0$ \\
Beginning & $36 \cdot 0$ & $18 \cdot 1$ \\
Mid- & $8 \cdot 4$ & $0 \cdot 6$ \\
Advanced & $0 \cdot 4$ & $0 \cdot 2$ \\
Post- & & \\
\hline \hline
\end{tabular}

original 'pre' and 'beginning' categories were collapsed into a single category (pre/beginning puberty) and, for boys, the original 'mid' and 'advanced/post' categories were collapsed into a single category (' $\mathrm{mid} /$ advanced'). Therefore, the three groups in girls were 'pre/beginning puberty', 'mid-puberty' and 'advanced/post puberty', whereas the three groups in boys represented 'pre-puberty', 'beginning puberty' and ' $\mathrm{mid} /$ advanced puberty'. All analyses are carried out separately for boys and girls.

Table 2 shows the associations between demographic characteristics including ethnicity, SES, age and BMI and pubertal stage. There was a significant relationship between SES and pubertal stage in boys, $\chi^{2}(N=1715)=18.92$, $\mathrm{df}=6, P<0.01$ and a similar trend in girls, $\chi^{2}(N=1316)=11 \cdot 64, \mathrm{df}=6, P=0 \cdot 07$, with the students from lower SES backgrounds being more likely to be advanced maturers. Among both boys and girls, the black students were more likely to be in the more advanced pubertal stages, compared with children from white and Asian backgrounds: boys, $\chi^{2}(N=1770)=22 \cdot 91$, $\mathrm{df}=6, \quad P<0.001 ; \quad$ girls, $\quad \chi^{2}(N=1327)=76 \cdot 54$, $\mathrm{df}=6, P<0 \cdot 001$.

The age range for Year 7 is $10 \cdot 3$ to 13.7 decimal years. The typical age of students in Year 7 is 11-12 years, the sample also included nine participants aged $<11$ and 10 participants aged $>12$. These represent children who have either been accelerated or held back at school As would be expected, the mean age increases across pubertal stages in girls, $F(2,1301)=$ $26 \cdot 20, P<0 \cdot 001$; and boys, $F(2,1720)=13 \cdot 00$, $P<0 \cdot 001$. Students who were advanced, and thus more developmentally mature, also had a higher BMI : girls, $F(2,1327)=48 \cdot 50, P<0 \cdot 001$; boys, $F(2,1775)=8 \cdot 55, P<0 \cdot 001$.

\section{Pubertal stage and health behaviours}

Table 2 also shows the raw data for the relationships between pubertal stage and health behaviours. These indicated that, in boys, a relationship existed between pubertal stage and high-fat food intake, $F(2,1719)=8 \cdot 22$, $P<0.001$, fruit and vegetable consumption, $F(2,1758)=3.64, P<0.05$, having tried smoking $\chi^{2}(N=1757)=26.61, \mathrm{df}=2, P<0.001$ and weekend exercise, $\chi^{2}(N=1723)=15.94, \mathrm{df}=4$, $P<0.01$. In girls a relationship was seen between pubertal stage and having tried smoking, $\chi^{2}(N=1313)=31 \cdot 47, \mathrm{df}=2, P<0 \cdot 001$.

In order to explore these relationships more rigorously a series of logistic and ordinal regression analyses were carried out to assess the odds of reporting each behaviour in relation to pubertal stage, controlling for age, SES, ethnicity, and BMI and including clustering for schools and weighting for design and missing data, as previously discussed. The lowest pubertal stage was used as the reference group. In the first sets of analyses, the gender-by-pubertal stage interactions were included in the model. These were significant or close to significant, for weekend exercise, days of exercise, high-fat food intake, and fruit and vegetable intake, although not for either of the smoking variables. In the light of these results, and because of the different groupings of pubertal stage in boys and girls, the analyses of the associations between pubertal stage and health behaviours were carried out separately for each gender. These results are shown in Tables 3 and 4.

The odds of smoking were higher in the more pubertally advanced students in both boys and girls. The pattern of odds ratios supported a graded effect across the stages, indicating that relative to students in the earliest pubertal stage, those at successively later stages were increasingly likely to have smoked. There was also a relationship between pubertal stage and nonsmokers' susceptibility to smoking in both boys 
Table 2. Descriptive statistics showing the relationship between pubertal stage, demographics, health behaviours, stress and psychological difficulties

\begin{tabular}{|c|c|c|c|c|c|c|}
\hline & \multicolumn{3}{|c|}{ Girls } & \multicolumn{3}{|c|}{ Boys } \\
\hline & \multicolumn{3}{|c|}{ Pubertal stage } & \multicolumn{3}{|c|}{ Pubertal stage } \\
\hline & $\begin{array}{l}\text { Pre/Beginning } \\
\quad(N=739)\end{array}$ & $\begin{array}{c}\text { Mid } \\
(N=482)\end{array}$ & $\begin{array}{l}\text { Advanced/Post } \\
\quad(N=118)\end{array}$ & $\begin{array}{c}\text { Pre } \\
(N=145)\end{array}$ & $\begin{array}{l}\text { Beginning } \\
(N=1307)\end{array}$ & $\begin{array}{l}\text { Mid/Advanced } \\
\quad(N=339)\end{array}$ \\
\hline \multicolumn{7}{|l|}{ SES } \\
\hline Low, \% & $50 \cdot 5$ & $39 \cdot 2$ & $10 \cdot 3$ & $3 \cdot 8$ & $71 \cdot 9$ & $24 \cdot 3$ \\
\hline Middle, \% & $52 \cdot 7$ & $36 \cdot 0$ & $11 \cdot 3$ & $7 \cdot 8$ & $71 \cdot 2$ & $21 \cdot 0$ \\
\hline High, \% & $59 \cdot 5$ & $33 \cdot 8$ & $6 \cdot 7$ & $8 \cdot 1$ & $73 \cdot 8$ & $18 \cdot 1$ \\
\hline Highest, \% & $58 \cdot 8$ & $34 \cdot 4$ & $6 \cdot 8$ & $10 \cdot 9$ & $72 \cdot 8$ & $16 \cdot 3$ \\
\hline \multicolumn{7}{|l|}{ Ethnicity } \\
\hline White, \% & $62 \cdot 6$ & $31 \cdot 8$ & $5 \cdot 6$ & $8 \cdot 9$ & $74 \cdot 3$ & $16 \cdot 8$ \\
\hline Black, \% & $35 \cdot 5$ & $46 \cdot 6$ & $17 \cdot 9$ & $5 \cdot 8$ & $66 \cdot 8$ & $27 \cdot 4$ \\
\hline Asian, $\%$ & $54 \cdot 3$ & $40 \cdot 0$ & $5 \cdot 7$ & $7 \cdot 8$ & $77 \cdot 1$ & $15 \cdot 1$ \\
\hline Mixed, \% & $50 \cdot 6$ & $38 \cdot 1$ & $11 \cdot 3$ & $5 \cdot 8$ & $67 \cdot 9$ & $26 \cdot 3$ \\
\hline \multicolumn{7}{|l|}{ Tried smoking, $\%$} \\
\hline No & $90 \cdot 0$ & $79 \cdot 5$ & $76 \cdot 7$ & $92 \cdot 3$ & $82 \cdot 6$ & $73 \cdot 4$ \\
\hline Yes & $10 \cdot 0$ & $20 \cdot 5$ & $23 \cdot 3$ & $7 \cdot 7$ & $17 \cdot 4$ & $26 \cdot 6$ \\
\hline \multicolumn{7}{|l|}{ Susceptibility to smoking, $\%$} \\
\hline No & $85 \cdot 8$ & $80 \cdot 8$ & $82 \cdot 0$ & $79 \cdot 5$ & $79 \cdot 6$ & $77 \cdot 6$ \\
\hline Yes & $14 \cdot 2$ & $19 \cdot 2$ & $18 \cdot 0$ & $20 \cdot 5$ & $20 \cdot 4$ & $22 \cdot 4$ \\
\hline \multicolumn{7}{|l|}{ Weekend exercise, \% } \\
\hline No days & $33 \cdot 5$ & $36 \cdot 5$ & $40 \cdot 0$ & $30 \cdot 7$ & $24 \cdot 8$ & $16 \cdot 3$ \\
\hline 1 day & $43 \cdot 1$ & $43 \cdot 0$ & $37 \cdot 3$ & $26 \cdot 3$ & $33 \cdot 2$ & $35 \cdot 3$ \\
\hline 2 days & $23 \cdot 4$ & $20 \cdot 5$ & $22 \cdot 7$ & $43 \cdot 1$ & $42 \cdot 0$ & $48 \cdot 3$ \\
\hline Age, mean (S.D.) & $11 \cdot 80(0 \cdot 32)$ & $11 \cdot 90(0 \cdot 32)$ & $11 \cdot 98(0 \cdot 31)$ & $11 \cdot 72(0 \cdot 34)$ & $11 \cdot 80(0 \cdot 36)$ & $11 \cdot 89(0 \cdot 38)$ \\
\hline BMI, mean (S.D.) & $19 \cdot 15(3 \cdot 56)$ & $20 \cdot 57(3 \cdot 73)$ & $22 \cdot 25(3 \cdot 67)$ & $18 \cdot 24(2 \cdot 75)$ & $18 \cdot 78(3 \cdot 21)$ & $19 \cdot 45(3 \cdot 58)$ \\
\hline Days/week exercised, mean (s.D.) & $3 \cdot 70(1 \cdot 78)$ & $3.63(1.76)$ & $3.94(2 \cdot 11)$ & $3.97(20.7)$ & $4 \cdot 19(2 \cdot 00)$ & $4 \cdot 33(2 \cdot 14)$ \\
\hline High-fat food intake, mean (s.D.) & $13 \cdot 77(4.90)$ & $14 \cdot 47(5 \cdot 10)$ & $14 \cdot 17(5 \cdot 34)$ & $14 \cdot 22(5 \cdot 41)$ & $15 \cdot 37(5 \cdot 47)$ & $16 \cdot 38(5 \cdot 77)$ \\
\hline Fruit/vegetable intake, mean (S.D.) & $4 \cdot 24(2 \cdot 26)$ & $4 \cdot 29(2 \cdot 41)$ & $4 \cdot 39(2 \cdot 66)$ & $4 \cdot 00(2 \cdot 30)$ & $4 \cdot 03(2 \cdot 32)$ & $4 \cdot 41(2 \cdot 64)$ \\
\hline Perceived stress, mean (s.D.) & $5 \cdot 70(2 \cdot 82)$ & $5 \cdot 79(2 \cdot 91)$ & $6 \cdot 47(3 \cdot 30)$ & $5 \cdot 34(2 \cdot 93)$ & $5 \cdot 29(2.98)$ & $5 \cdot 54(3 \cdot 16)$ \\
\hline Psychological difficulties, mean (s.D.) & $11 \cdot 80(5 \cdot 04)$ & $12 \cdot 24(5 \cdot 07)$ & $12 \cdot 66(4 \cdot 85)$ & $12 \cdot 19(4 \cdot 87)$ & $12 \cdot 05(5 \cdot 14)$ & $12 \cdot 57(5 \cdot 36)$ \\
\hline
\end{tabular}

and girls. This was difficult to interpret for girls, but again suggested in boys that susceptibility to smoking increased with pubertal stage.

For exercise behaviour, a significant relationship was found between pubertal stage and weekend exercise in boys. The more pubertally advanced boys were more likely to take exercise at the weekend. Although non-significant the results from the girls' analyses suggested a reversal of this pattern with girls taking less weekend exercise as they become more developed. Effects for overall days of exercise were not significant in either girls or boys, although the results showed the same direction for boys.

For food intake, there was a significant relationship between pubertal stage and high-fat food intake in boys with the more pubertally advanced boys consuming larger amounts of high-fat food, but no significant relationship between pubertal stage and high-fat food intake in girls. There was no association between pubertal stage and fruit and vegetable intake in either boys or girls.

\section{Mediation by stress and psychological difficulties}

For a variable to be a potential mediator it has to be associated with both the independent and the dependent variables (Baron \& Kenny, 1986). Mean scores for the stress and psychological difficulties scales across the pubertal groups are shown in Table 2. There was a significant association between pubertal stage and stress scores in girls, $F(2,1324)=3 \cdot 50, P<0 \cdot 05$, and a trend for psychological difficulties to be higher in those who were more pubertally advanced, $F(2,1328)=2 \cdot 08, P=0 \cdot 13$. The pattern of scores for boys was neither linear nor statistically significant, although the highest level of stress and psychological difficulties was in the most pubertally advanced group. 
Table 3. Summary of regression analyses showing the associations between health behaviours and pubertal stage in boys: Model 1 controlling for SES, age, ethnicity, BMI and Model 2 additionally controlling for perceived stress and psychological difficulties - odds ratios $(95 \%$ CI $)$

\begin{tabular}{|c|c|c|c|c|}
\hline & \multirow[b]{2}{*}{$N$} & \multicolumn{3}{|c|}{ Pubertal stage } \\
\hline & & Pre & Beginning & Mid/Advanced \\
\hline \multicolumn{5}{|l|}{ Model 1} \\
\hline Tried smoking & 1244 & $1 \cdot 0$ & $2 \cdot 39(1 \cdot 28-4 \cdot 45)^{* *}$ & $4 \cdot 41(2 \cdot 18-8 \cdot 91)^{* * *}$ \\
\hline Susceptibility to smoking $\dagger$ & 1057 & $1 \cdot 0$ & $2.37(1.12-5 \cdot 04)^{*}$ & $2 \cdot 55(1 \cdot 04-6 \cdot 28)^{*}$ \\
\hline Days/week exercised & 1259 & $1 \cdot 0$ & $1.22(0 \cdot 90-1 \cdot 63)$ & $1.31(0 \cdot 78-2 \cdot 18)$ \\
\hline Weekend exercise & 1195 & $1 \cdot 0$ & $1 \cdot 21(0 \cdot 89-1 \cdot 65)$ & $2 \cdot 11(1 \cdot 34-3 \cdot 33)^{* *}$ \\
\hline Fruit and vegetable intake & 1254 & $1 \cdot 0$ & $1.08(0 \cdot 79-1 \cdot 48)$ & $1 \cdot 30(0 \cdot 96-1 \cdot 75)$ \\
\hline High-fat food intake & 1216 & $1 \cdot 0$ & $1 \cdot 54(1.08-2 \cdot 20)^{*}$ & $2 \cdot 39(1 \cdot 52-3 \cdot 70)^{* * *}$ \\
\hline \multicolumn{5}{|l|}{ Model 2} \\
\hline Tried smoking & 1229 & $1 \cdot 0$ & $2 \cdot 23(1 \cdot 17-4 \cdot 26)^{*}$ & $4 \cdot 17(2 \cdot 02-8 \cdot 61)^{* * *}$ \\
\hline Weekend exercise & 1184 & $1 \cdot 0$ & $1.24(0.90-1.72)$ & $2 \cdot 19(1 \cdot 39-3 \cdot 47)^{* *}$ \\
\hline High-fat food intake & 1203 & $1 \cdot 0$ & $1.68(1.18-2.39)^{* *}$ & $2 \cdot 48(1.63-3 \cdot 86)^{* * *}$ \\
\hline
\end{tabular}

$\dagger$ Among never smokers.

* $P<0 \cdot 05 ; * * \quad P<0 \cdot 01$; *** $P<0 \cdot 001$.

Table 4. Summary of regression analyses showing the associations between health behaviours and pubertal stage in girls: Model 1 controlling for SES, age, ethnicity, BMI and Model 2 additionally controlling for perceived stress and psychological difficulties - odds ratios $(95 \% \mathrm{CI})$

\begin{tabular}{|c|c|c|c|c|}
\hline & \multicolumn{4}{|c|}{ Pubertal stage } \\
\hline & $N$ & Pre & Beginning & Mid/Advanced \\
\hline \multicolumn{5}{|l|}{ Model 1} \\
\hline Tried smoking & 1603 & $1 \cdot 0$ & $2 \cdot 36(1 \cdot 32-4 \cdot 25)^{* *}$ & $2.64(1.09-6 \cdot 41)^{*}$ \\
\hline Susceptibility to smoking $\dagger$ & 1303 & $1 \cdot 0$ & $1 \cdot 60(1 \cdot 08-2 \cdot 34)^{*}$ & $1 \cdot 37(0 \cdot 77-2 \cdot 45)$ \\
\hline Days/week exercised & 1628 & $1 \cdot 0$ & $0 \cdot 90(0 \cdot 73-1 \cdot 13)$ & $1 \cdot 21(0 \cdot 71-2 \cdot 03)$ \\
\hline Fruit and vegetable intake & 1606 & $1 \cdot 0$ & $1 \cdot 01(0 \cdot 71-1 \cdot 43)$ & $0 \cdot 88(0 \cdot 52-1 \cdot 49)$ \\
\hline High-fat food intake & 1574 & $1 \cdot 0$ & $1 \cdot 22(0 \cdot 95-1 \cdot 58)$ & $1 \cdot 23(0 \cdot 88-1 \cdot 73)$ \\
\hline \multicolumn{5}{|l|}{ Model 2} \\
\hline Tried smoking & 1573 & $1 \cdot 0$ & $2 \cdot 56(1 \cdot 45-4 \cdot 54)^{* *}$ & $2 \cdot 42(1 \cdot 07-5 \cdot 49)^{*}$ \\
\hline Weekend exercise & 1552 & $1 \cdot 0$ & $0 \cdot 80(0 \cdot 60-1 \cdot 07)$ & $0 \cdot 62(0 \cdot 31-1 \cdot 24)$ \\
\hline High-fat food intake & 1547 & $1 \cdot 0$ & $1 \cdot 17(0 \cdot 92-1 \cdot 51)$ & $1 \cdot 13(0 \cdot 77-1 \cdot 67)$ \\
\hline
\end{tabular}

To check for associations between stress or psychological difficulties and health behaviours we used Pearson correlations, which showed that they were significantly associated with each of the health behaviours that were associated with pubertal stage, that is, having tried smoking, weekend exercise and high-fat intake. Stress was modestly but significantly associated with having tried smoking $(r=0.09, P<0.001)$ doing less weekend exercise $(r=-0.06, P<0.05)$ and higher intake of fatty foods $(r=0 \cdot 10, P<0 \cdot 001)$ in boys. The same patterns emerged for associations with psychological difficulties (smoking, $r=0 \cdot 18, P<0.001$; exercise, $r=-0 \cdot 06, P<0.01$; intake of fatty foods, $r=0.13, P<0.001)$. The results were very similar for girls showing significant associations with stress (smoking, $r=$ $0.11, P<0.001$; exercise, $r=-0.08, P<0.01$; intake of fatty foods, $r=0 \cdot 10, P<0 \cdot 001)$ and with psychological difficulties (smoking, $r=0 \cdot 16$, $P<0.001$; exercise, $r=-0.07, P<0.01$; intake of fatty foods, $r=0 \cdot 14, P<0 \cdot 001)$.

Given that the criteria for mediation were met, logistic and ordinal regressions were carried out controlling for stress and psychological difficulties to see if this reduced the variance 
associated with pubertal stage (see Tables 3 and 4 , Model 2). In the interests of symmetry, these were done for both boys and girls, even though the association between pubertal stage and stress in boys was less clear cut. Looking at the odds ratios and confidence intervals for pubertal stage, it is clear that including these factors, although slightly changing the values, did not have a substantial impact. Therefore, differences in stress and psychological difficulties between pubertal stages did not seem to be the key to the variation in health behaviours linked with puberty.

\section{DISCUSSION}

The results of this study support the hypothesis that pubertal stage was related to health behaviour in a large sample of adolescents although the patterning of results varied both by behaviour and gender. Being more pubertally advanced in boys was associated with a greater likelihood of smoking and a less healthy diet, but higher levels of exercise. In girls, more advanced puberty was linked with higher smoking, but there was little association with either diet or exercise. The association between pubertal stage and health behaviours, where it was seen, generally showed a graded effect, such that the likelihood of engaging in a particular behaviour changed incrementally with increases in pubertal stage.

The results on smoking status and susceptibility to smoking replicated other findings in this area (Tschann et al. 1994; Gritz et al. 1998; Harrell et al. 1998; Dick et al. 2000). For exercise behaviour, advanced puberty was associated with more weekend exercise in boys but not in girls. In girls there was the possibility that weekend exercise may actually decrease with pubertal stage, although this was a non-significant result. The results reflect established gender differences in exercise participation among adolescents (Lasheras et al. 2001). The results also support the suggestion that higher pubertal stage is associated with an increase in sedentary activity among girls, but not boys (Bradley et al. 2000). The variable measuring 'days per week exercised' produced no significant results. This was probably because this variable is confounded with compulsory physical education at school, which varies between schools and does not necessarily index voluntary participation in exercise. Exercise outside school context may be more important, as it indicates an adolescent's deliberate choice to exercise as part of their leisure/social time. Pubertal stage was associated with high-fat food intake only in boys in our sample. The more developed boys may simply need to eat more as they are older and taller. Other studies have suggested that this gradient in intake disappears after controlling for body weight (Clavien et al. 1996) but in our data, the effect persisted after controlling for BMI. These findings suggest that pubertal development in boys is associated with an increasingly poor diet. This increase in fat intake may be related to the greater independence of older children to make food choices as they decrease the amount of meals eaten at home (Gillman et al. 2000). There was no relationship between fruit and vegetable consumption and pubertal stage in either boys or girls, so although previous studies have shown decreased consumption associated with age (Vereecken \& Maes, 2000), our data suggest that this is not related to the pubertal changes occurring at this time.

The main aim of the present study was to test whether the associations between pubertal stage and health behaviours were linked to puberty's associations with either perceived stress or emotional and behavioural difficulties as measured by the SDQ. A relationship was seen between stress and pubertal stage in girls, although no such relationship was found in boys. Smaller effects between puberty and stress in boys may have gone undetected due to the low reliability of the PSS in this sample. However, the SDQ also failed to detect a relationship, although for both measures the most stress and difficulties were detected among the most advanced male puberty group. The boys were overall less developed than the girls. The relationship with stress and psychological difficulties may only emerge among more advanced puberty groups than the boys represented at this age. Therefore, there may be value in exploring this relationship further using longitudinal work which tracks these groups over time. Having noted these limitations, it was still clear from the logistic regression analyses that these variables did not mediate the relationship between pubertal stage and health behaviours in either gender. On the basis of the results shown here, 
an alternative explanation for the link between pubertal stage and health behaviours must be found.

Although not tested here, it may be that other social, rather than emotional, processes have a role to play in explaining the health behaviour differences. Early maturation has been associated with social processes, e.g. socialization with older peers, greater peer pressure, emulating 'adult' type behaviour (Silbereisen et al. 1989) that may result in behavioural changes. Behaviours such as smoking and eating outside of the home are associated with a more 'adult' or 'independent' lifestyle and the changes in behaviour seen in this study could demonstrate an attempt by the adolescent to assert their independence.

There were some limitations to the conclusions that can be drawn from this study. As discussed, there were problems with the measurement of perceived stress, which have meant that the mediational hypothesis was not tested as rigorously as it could have been. The results from this study derive from crosssectional data which has meant that some relationships have remained ambiguous. For example, the results found here could reflect differences in pubertal timing rather than differences in levels of pubertal stage. That is, those who are the most pubertally advanced at this age, are also the group that have developed relatively early compared to their peer group. As the current pre/beginning/mid pubertal groups progress through the higher pubertal stages they may display similar behaviour to the current advanced/post-pubertal groups, supporting a maturational model. On the other hand those who are currently more developed than their peers might always stand out as a distinct group, suggesting an effect of pubertal timing. It will be possible to pursue this line of enquiry longitudinally with future data from the HABITS project.

This study was important for a number of reasons. First, comparatively little research has examined smoking uptake as part of a wider issue of adoption of health behaviours such as exercise and dietary choice. There is some debate as to whether smoking is better conceived as a health behaviour or is more closely allied with problem/delinquent behaviour established during this period (Turbin et al. 2000).
The analyses here have shown that dietary behaviours in boys and exercise in girls are related to pubertal status in a similar way to smoking behaviour, giving some support to the health behaviour view. However, there was no association with diet in girls and a positive association with exercise in boys, suggesting complex pathways best understood on a behaviour by behaviour basis. Secondly, this study used a large sample comprising both boys and girls. Much research to date which considers pubertal stage and behaviour has focused either on boys or girls but not both. Incorporating both genders into the analyses has enabled a comparison to be made between genders and there were a number of important differences. Thirdly, this study provided the opportunity to explore a possible causal explanation for the relationship between puberty and health behaviour, namely that puberty related increases in emotional stress or distress were responsible for the changes in behaviour. This has been explored in detail in only one previous study (i.e. Tschann et al. 1994). The results here have substantiated the conclusions of that study that emotional distress does not mediate the relationship between puberty and behaviour.

In conclusion, more advanced puberty was found to be associated with changes in health behaviours including smoking, exercise and diet. The results suggest that maturity is a largely unfavourable event for both boys and girls in terms of the health behaviours that are established during adolescence, with the notable exception of exercise behaviour in boys. The implications for those involved in health promotion with adolescents, including school staff, are that early-maturing adolescents need extra support. This may be to help them withstand exposure to new social pressures, or to come to terms with the physical changes. The initiation of these behaviours is probably unrelated to issues of psychological stress and further work could establish more clearly whether, and in what way, pubescent adolescents are exposed to unhelpful social influences.

\section{REFERENCES}

Alsaker, F. (1996). Annotation: the impact of puberty. Journal of Child Psychology and Psychiatry 37, 249-258.

Baron, R. M. \& Kenny, D. A. (1986). The moderator-mediator variable distinction in social psychological research: conceptual, 
strategic and statistical consideration. Journal of Personality and Social Psychology 51, 1173-1182.

Benowitz, N. L. (1996). Cotinine as a biomarker of environmental tobacco smoke exposure. Epidemiology Review 18, 188-204.

Bradley, C. B., McMurray, R. G., Harrell, J. S. \& Deng, S. (2000). Changes in common activities of 3rd through 10th graders: the CHIC study. Medicine and Science in Sports and Exercise 32, 2071-2078.

Brooks-Gunn, J., Warren, M. P., Rosso, J. \& Garigulo, J. (1987). Validity of self-report measures of girl's pubertal status. Child Development 58, 829-841.

Caspi, A. \& Moffitt, T. E. (1991). Individual differences are accentuated during periods of social change: the sample case of girls at puberty. Journal of Personality and Social Psychology 1, 157-168.

Clavien, H., Theintz, G., Rizzoli, R. \& Bonjour, J.-P. (1996). Does puberty alter dietary habits in adolescents living in a Western society? Journal of Adolescent Health 19, 68-75.

Cohen, S. \& Williamson, G. (1988). Perceived stress in a probability sample of the United States. In The Social Psychology of Health (ed. S. Spacapan and S. Oskamp), pp. 31-67. Sage: California.

Cohen, S., Kamarck, T. \& Mermelstein, R. (1983). A global measure of perceived stress. Journal of Health and Social Behaviour $\mathbf{2 4}$ 385-396.

Dick, D. M, Rose, R. J., Viken, R. J. \& Kaprio, J. (2000). Pubertal timing and substance use: Associations between and within families across late adolescence. Developmental Psychology 36, 180-189.

Gillman, M. W., Rifas-Shiman, S. L., Frazier, L., Rockett, H. R., Camargo, C. A., Field, A. E., Berkey, C. S. \& Colditz, G. A. (2000). Family dinner and diet quality among older children and adolescents. Archives of Family Medicine 9, 235-240.

Goddard, E. \& Higgins, V. (1999). Smoking, Drinking and Drug use Among Young Teenagers in 1998. UK National Smoking Surveys Volume 1. The Stationery Office: London.

Goodman, R., Meltzer, H. \& Bailey, V. (1998). The strengths and difficulties questionnaire: a pilot study on the validity of the selfreport version. European Child and Adolescent Psychiatry 7, 125-130.

Goodson, P., Evans, A. \& Edmundson, E. (1997). Female adolescents and onset of sexual intercourse: a theory-based review of research from 1984 to 1994. Journal of Adolescent Health 21, $147-156$.

Gritz, E. R., Prokhorov, A. V., Suchanek Hudmon, K., Chamberlain, R., Taylor, W., Di Clemente, C., Johnston, D., Hu, S., Jones, L., Mullin Jones, M., Roseblum, C., Ayars, C. \& Amos, C. (1998). Cigarette smoking in a multiethnic population of youth: Methods and baseline findings. Preventive Medicine 27, 365-384.

Harrell, J. S., Bangdiwala, S. I., Deng, S., Webb, J. \& Bradley, C. (1998). Smoking initiation in youth: the role of gender, race, socioeconomics and developmental status. Journal of Adolescent Health 1998 23, 271-279.

Hayward, C., Gotlib, I. H., Schraedley, P. K. \& Litt, I. (1999). Ethnic differences in the association between pubertal status and symptoms of depression in adolescent girls. Journal of Adolescent Health 25, 143-149.

Heath, G. W., Pate, R. R. \& Pratt, M. (1993). Measuring physical activity among adolescents. Centres for Disease Control and Prevention Public Health Reports 108, 42S-46S.

Laberge, L., Petit, D., Simard, C., Vitaro, F. \& Tremblay, R. (2001). Development of sleep patterns in early adolescence. Journal of Sleep Research 10, 59-67.

Lasheras, L., Aznar, S. \& Merion, B. (2001). Factors associated with physical activity among Spanish youth through the national health survey. Preventive Medicine 32, 455-464.

Lindquist, C. H., Reynolds, K. D. \& Goran, M. I. (1999). Sociocultural determinants of physical activity among children. Preventive Medicine 29, 305-312.

McCabe, M. P., Ricciardelli, L. A. \& Banfield, S. (2001). Body image, strategies to change muscles and weight, and puberty.
Do they impact on positive and negative affect among adolescent boys and girls? Eating Behaviours 2, 129-149.

Neumark-Sztainer, D., Story, M., Resnick, M. D. \& Blum, R. (1996). Correlates of inadequate fruit and vegetable consumption among adolescents. Preventive Medicine 25, 497-505.

Petersen, A. C. \& Taylor, B. (1980). The biological approach to adolescence: biological change and psychological adaptation. In Handbook of Adolescent Psychology (ed. J. Adelson), pp. 117-155. Wiley: New York.

Petersen, A. C., Crockett, L., Richards, M. \& Boxer, A. (1988). A self-report measure of pubertal status: reliability, validity and initial norms. Journal of Youth and Adolescence 17, 117-132

Pierce, J. P., Choi, W. S., Gilpin, E. A., Farkas, A. \& Merritt, K. (1996). Validation of susceptibility as a predictor of which adolescents take up smoking in the United States. Health Psychology 15, 355-361.

Ricciaridelli, L. A., McCabe, M. P. \& Banfield, S. (1999). Body image and body change methods in adolescent boys: role of parents, friends, and the media. Journal of Psychosomatic Research 49, $189-197$.

Roe, L., Strong, C., Whiteside, C., Neil, A. \& Mant, D. (1994). Dietary intervention in primary care: validity of the DINE method for diet assessment. Family Practice 11, 375-381.

Rolland-Cachera, M.-F., Bellisle, F. \& Deheeger M. (2000). Nutritional status and food intake in adolescents living in Western Europe. European Journal of Clinical Nutrition 54, 41S-46S.

Silbereisen, R. K., Petersen, A. C., Albrecht, H. T. \& Kracke, B. (1989). Maturational timing and the development of problem behaviour: longitudinal studies in adolescence Journal of Early Adolescence 9, 247-268.

Stattin, H. \& Magnusson, D. (1990). Pubertal Maturation in Female Development. Erlbaum: New Jersey.

Steinberg, L. \& Sheffield-Morris, A. (2001). Adolescent development. Annual Review of Psychology 52, 83-110.

Sweeting, H., Anderson, A. \& West, P. (1994). Socio-demographic correlates of dietary habits in mid to late adolescence. European Journal of Clinical Nutrition 48, 736-748.

Tanner, J. M. (1962). Growth at Adolescence: With a General Consideration of the Effects of Hereditary Environmental Factors upon Growth and Maturation from Birth to Maturity, 2nd edn. Blackwell Scientific: Oxford

Tschann, J. M., Adler, N. E., Irwin, C. E., Millstein, S., Turner, R. \& Kegeles, S. (1994). Initiation of substance use in early adolescence: the roles of pubertal timing and emotional distress. Health Psychology 13, 326-333.

Turbin, M. S., Jessor, R. \& Costa, F. M. (2000). Adolescent cigarette smoking: health-related behaviour or normative transgression? Prevention Science 1, 115-124.

Van Wersch, A., Trew, K. \& Turner, I. (1992). Post-Primary school pupils' interest in physical education: age and gender differences. British Journal of Educational Psychology 62, 56-72.

Vereecken, C. \& Maes, L. (2000). Eating habits, dental care and dieting. In Health and Health Behaviour among Young People, Health Behaviour in School-aged Children: A WHO CrossNational Study (HBSC) International Report (ed. C. Currie, K. Hurrelmann and R. Smith), pp. 83-85. World Health Organization: Copenhagen.

Wardle, J., Parmenter, K. \& Waller, J. (2000). Nutrition knowledge and food intake. Appetite 34, 269-275.

Wardle, J., Robb, K. \& Johnson, F. (2002). Assessing SES in adolescents: the validity of a home affluence scale. Journal of Epidemiology and Community Health 56, 595-599.

Wardle, J., Jarvis, M. J., Steggles, N., Sutton, S., Williamson, S., Farrimond, H., Cartwright, M. \& Simon, A. E. (2003). Socioeconomic disparities in cancer-risk behaviours in adolescence: baseline results from the Health and Behaviour in Teenagers Study (HABITS). Preventive Medicine 36, 721-730.

Williams, J. M. \& Dunlop, L. C. (1999). Pubertal timing and self-reported delinquency among male adolescents. Journal of Adolescence 22, 157-171. 